\title{
Multivessel coronary artery disease and poor left ventricle function: It is consistent and clear, coronary artery bypass grafting wins again
}

\author{
Saina Attaran, MD, William S. Weintraub, MD, and Vinod H. Thourani, MD
}

From the Department of Cardiac Surgery, MedStar Heart and Vascular Institute, Georgetown University, Washington, DC.

Disclosures: Authors have nothing to disclose with regard to commercial support.

Received for publication April 29, 2018; revisions received April 29, 2018; accepted for publication April 30, 2018; available ahead of print June 15, 2018.

Address for reprints: Vinod H. Thourani, MD, MedStar Heart and Vascular Institute, 110 Irving St, NW, Rm 6D15G, Washington, DC 20010 (E-mail: vinod.h.thourani@medstar.net).

J Thorac Cardiovasc Surg 2018;156:1406-7 $0022-5223 / \$ 36.00$

Copyright (C) 2018 by The American Association for Thoracic Surgery https://doi.org/10.1016/j.jtcvs.2018.04.120

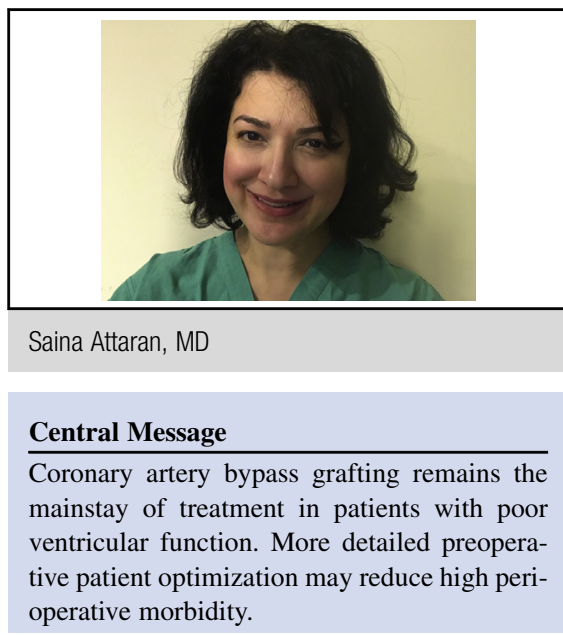

See Article page 1410 .
Superiority of coronary artery bypass grafting (CABG) to medical therapy in patients with impaired ventricular function (ie, ejection fraction $\leq 35 \%$ ) has been shown in clinical trials. ${ }^{1,2}$ Observational studies have also demonstrated greater survival in patients with an impaired left ventricle undergoing $\mathrm{CABG}$ compared with those that are treated with percutaneous coronary intervention (PCI). ${ }^{3,4}$ Although these studies unanimously demonstrated that the incidence of early stroke, renal failure, and other complications were higher in the $\mathrm{CABG}$ group, having a better survival rate favors $\mathrm{CABG}$ over PCI in the treatment of patients with coronary artery disease and poor ventricular function.

Iribarne and colleagues ${ }^{5}$ conducted an extensive multicenter observational analysis of more than 70,000 patients with ejection fraction $\leq 35 \%$ with 2 - or 3 -vessel disease who underwent either CABG or PCI between 2004 and 2014 in the Northern New England Cardiovascular Disease Study Group. The authors showed a lower incidence of long-term all-cause and cardiac mortality with $\mathrm{CABG}$, but demonstrated more complications at 30 days compared with PCI. ${ }^{5}$ These results are consistent with previous data comparing CABG and PCI in this patient population. ${ }^{3,4}$ In addition, patients in the PCI group had similar survival rates as those undergoing $\mathrm{CABG}$ at 30 days but a higher rate of reintervention.

What makes this study unique is the large sample size and long-term follow-up. This permitted robust subgroup analyses in patients with ejection fraction $<25 \%$, women, and age $\geq 65$ years, all with similar findings noting improved survival with CABG. Thus, the question is: Should all patients with 2- or 3-vessel disease and a poorly functioning ventricle be referred for $\mathrm{CABG}$ despite the 30 day mortality rate of $3.5 \%$, acute kidney injury rate of just under $40 \%$, and stroke rate of $3 \%$ ? The authors should be congratulated on such an eloquent analysis. \section{.}

. 
unmeasured confounders that could account for the different outcomes in the 2 groups. ${ }^{5}$ It is possible that those patients undergoing PCI were turned down by a cardiac surgeon; information not easily gleaned by demographic characteristics and matching. Such confounders could be frailty or details of the coronary anatomy. Thus, the authors were careful to present these results as an association, not a causal relationship. Although we agree that the comparison of PCI versus CABG for patients with a poorly functioning left ventricle should be addressed in a randomized trial, this may be too expensive and the logistic difficulties of such a trial could be formidable. For any single patient, the issue of PCI versus CABG may not be in equipoise, which would lead to recruitment difficulties.

Current data show a strong association between CABG and improved long-term survival compared with $\mathrm{PCI}$ in patients with poor ventricular function. Nonetheless, careful patient selection and optimal pre- and postoperative management are required to limit complications.

\section{References}

1. Velazquez EJ, Lee KL, O'Connor CM, Oh JK, Bonow RO, Pohost GM, et al The rationale and design of the surgical treatment for ischemic heart failure (STICH) trial. J Thorac Cardiovasc Surg. 2007;134:1540-7.

2. Velazquez EJ, Lee KL, Deja MA, Jain A, Sopko G, Marchenko A, et al Coronary-artery bypass surgery in patients with left ventricular dysfunction. N Engl J Med. 2011;364:1607-16.

3. Weintraub WS, Grau-Sepulveda MV, Weiss JM, O'Brien SM, Peterson ED Kolm P, et al. Comparative effectiveness of revascularization strategies. $N$ Engl J Med. 2012;366:1467-76.

4. Buchanan GL, Chieffo A, Meliga E, Mehran R, Park SJ, Onuma Y, et al Comparison of percutaneous coronary intervention (with drug-eluting stents) versus coronary artery bypass grafting in women with severe narrowing of the left main coronary artery (from the Women-Drug-Eluting stent for LefT main coronary Artery disease Registry). Am J Cardiol. 2014;113:1348-55.

5. Iribarne A, DiScipio AW, Leavitt BJ, Baribeau YR, McCullough JN, Weldner PW, et al. Comparative effectiveness of coronary artery bypass grafting versus percutaneous coronary intervention in a real-world Surgical Treatment for Ischemic Heart Failure trial population. J Thorac Cardiovasc Surg. 2018;156:1410-21.e2. 